\title{
Circulating sheath currents in flat formation underground power lines
}

\author{
J.R. Riba Ruiz ${ }^{1}$, Antoni Garcia ${ }^{2}$, X. Alabern Morera ${ }^{3}$ \\ ${ }^{1}$ Department d'Enginyeria Elèctrica, UPC \\ EUETII-"L'Escola d'Adoberia" \\ Plaça del Rei 15, 08700 Igualada (Spain) \\ phone:+34 938 035300, fax:+34 938 031589, e-mail: jordi@euetii.upc.edu \\ ${ }^{2}$ Department d'Enginyeria Elèctrica, UPC \\ C./ Colom 11, 08222 Terrassa (Spain) \\ phone: +34 937 398155, garciae@ee.upc.edu \\ ${ }^{3}$ Department d'Enginyeria Elèctrica, UPC \\ C./ Colom 11, 08222 Terrassa (Spain) \\ phone: +34937398155, alabern@ee.upc.edu
}

\begin{abstract}
Three-phase underground power lines can induce voltages and currents in their recover sheaths. The sheath induced currents are undesirable and generate power losses and reduce the cable ampacity whereas the induced voltages can generate electric shocks to the workers that keep the power line. This means that when dealing with three-phase underground power lines, it is very important to know the sheath currents (called circulating currents) that can circulate throughout the sheath of the cables. It is very useful to know their values. The values of the circulating currents depend on different parameters, such as the sheath grounding system, the geometry of the cables, the gap between them, etc. In this work, different geometries of flat configuration underground three-phase power lines have been studied. For each geometry it has been computed the sheath circulating currents in each cable of the power line.
\end{abstract}

\section{Key words}

Sheath currents, cable ampacity, power cables, underground power lines.

\section{Introduction}

The raising environmental pressure is creating new markets for the power transmission systems based on very high voltage XLPE-isolated cables. Nowadays XLPE-cables are being applied up to $500 \mathrm{kV}$. In many countries high voltage overhead power lines are not allowed in large cities which are densely populated. These mentioned countries don't authorize overhead power lines in populated areas and promote the progressive burying of the existent overhead power lines in such areas. Catalunya is an example of this situation, and its government wants that in few years almost all the high voltage power lines in populated areas will be buried.

Therefore, it is not desirable an indiscriminate burying of the high voltage power lines. The burying of the power lines should be carried out mainly in populated and in ecological areas, whereas in rural areas the electric power lines should be overhead.
In this paper the influence of the metallic sheath in the magnetic field generated by underground single core power cables is studied. When dealing with underground power cables, sheath circulating currents can be induced. These currents produce power losses in the sheaths and decrease the ampacity (capacity of carrying current) of the cables. The circulating sheath currents generate a magnetic field that adds to the cable magnetic field. In this paper the modification of the total magnetic field is studied.

\section{Electric characteristics of the analyzed cables}

The high voltage cable studied in this work has the components shown in figure 1.

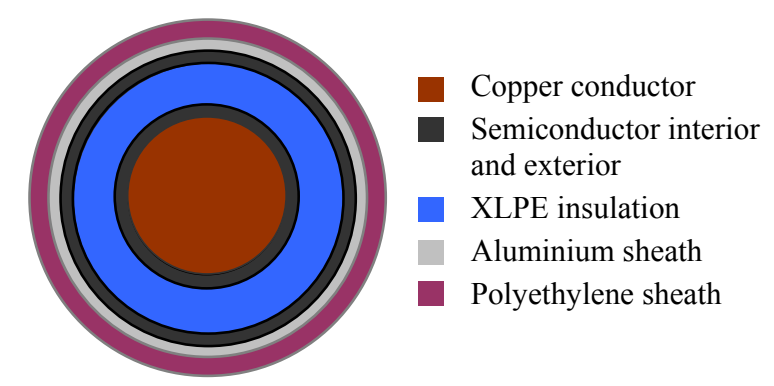

Figure 1. Diagram of a single core cable

In this section, it has been dealt with cables that have the features shown in table I.

TABLE I. Main characteristics of the single core $110 \mathrm{kV}$ cable under study

\begin{tabular}{c}
\hline Conductor's material: copper \\
\hline Diameter of the conductor: $32.8 \mathrm{~mm}$ \\
\hline Resistivity of the conductor $\left(20^{\circ} \mathrm{C}\right): 28,3 \mu \Omega / \mathrm{m}$ \\
\hline Resistivity of the conductor $\left(70^{\circ} \mathrm{C}\right): 33,86 \mu \Omega / \mathrm{m}$ \\
\hline Number of strings of the conductor: 127 \\
\hline Coefficient of the cable: $\alpha_{127}=0.776$ \\
\hline Sheath's material: aluminium \\
\hline Diameter of the sheath: $48 \mathrm{~mm}$ \\
\hline Resistivity of the conductor $\left(20^{\circ} \mathrm{C}\right): 0,18 \mathrm{~m} \Omega / \mathrm{m}$ \\
\hline
\end{tabular}




\section{Sheath bonding methods}

When the sheaths of single-conductor cables are bonded to each other, as is common practice for multiconductor cables, the induced voltage causes current to flow in the completed circuit. This current generates losses in the sheaths. Various methods of bonding may be used for the purpose of minimizing sheath losses. Formerly, where special bonding was employed for the prevention of sheath losses on lead-sheathed cables without an insulating jacket, the sheaths were subjected to ac voltages, and the bonding was designed to keep the magnitude of the induced voltages within small limits so as to prevent the possibility of sheath corrosion due to ac electrolysis.

\subsection{Single-point bounding}

It is the simplest system of bonding and it is shown in figure 6 . The metallic sheaths are grounded at only one point along their length. At all other points, a voltage will appear from sheath to ground that will be a maximum at the farthest point from the ground bond. Since there is no closed sheath circuit current no sheath circulating current loss occurs, but sheath eddy loss will still be present.

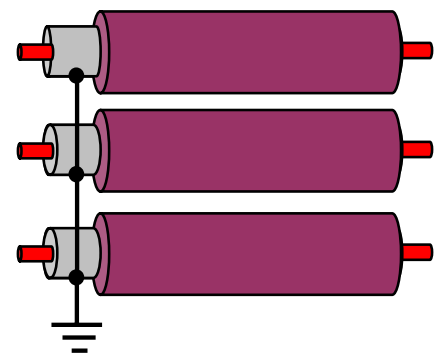

Figure 2. Single-point bonding

\subsection{Multiple-point bonding}

When dealing with a multiple-point bonding scheme, as shown in figure 7 , the metallic sheaths are grounded at least at the two extremes of the cable. This system doesn't allow high values of the induced voltages in the metallic sheaths. In this situation, appear sheath circulating currents because of there is a closed circuit between the sheath and the return path through the ground. This is the scheme studied in this paper.

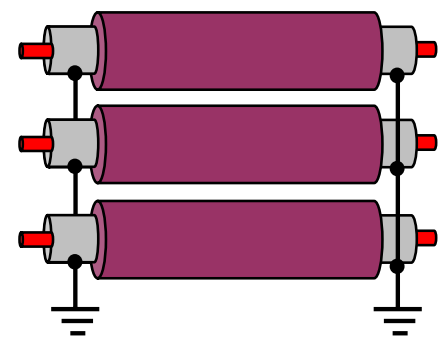

Figure 3. Multiple-point bonding

The circulating currents produce different effects:

- Circulating sheath currents generate power losses by heating.
- Circulating sheath currents reduce the cables ampacity (current flow capacity) due to thermal effects.

- Circulating sheath currents generate a magnetic field that adds to the cable magnetic field. In this paper the modification of the total magnetic field is studied.

\subsection{Crossbonding}

The crossbonding consists on dividing the length of the cable in two groups of three equal sections (called minor sections). It breaks the electric continuity of each sheath. Three minor sections make up a major section, where the sheaths are interconnected between them and also are bonded to earth. The length of each section must be a third part of the total length of the distance between two earth-connections of the cable.

The crossbonding system allows to eliminate or at least to reduce the sheath currents.

Figure 4 shows a flat formation power line with crossbonding.

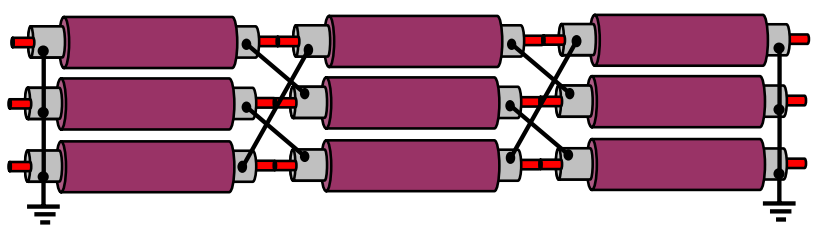

Figure 4. Crossbonding

When dealing with triangular formation power cables, crossbonding eliminates totally the sheath currents.

When dealing with flat formation power cables, the crossbonding system doesn't eliminate totally the sheath currents due to the lack of symmetry of the three cables, but crossbonding reduces outstandingly the sheath currents.

\subsection{Crossbonding with transposition}

If the crossbonding scheme doesn't allow to reduce totally the sheath currents, the crossbonding with transposition allows to reduce even more the sheath currents. It consists on transposing cyclically the three main conductors in each minor section. This is the more suitable disposition in order to reduce the sheath currents.

Figure 5 shows a flat formation power line with crossbonding with transposition.

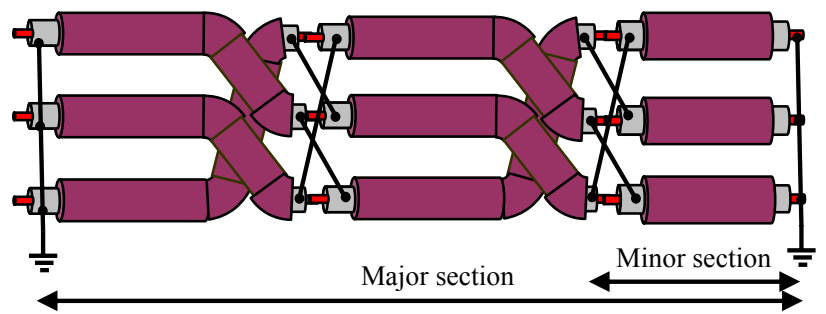

Figure 5. Crossbonding with transposition 


\section{Calculations}

In this section the conductor and sheath currents of several formations of three-phase power lines are calculated. In all the cases it has been assumed that the sheaths of the cables are grounded in the two extremes.

The calculations have been carried out by following the formulation explained in reference [1].

\subsection{Example 1}

In this example, it has been considered a three-phase flat line with a single conductor in each phase $(p=1)$, with configuration RST and an intensity of $100 \mathrm{~A}$.

Table II shows the sheath currents computed by applying the method explained in reference [1]. It has been considered two situations, $s=0,1 \mathrm{~m}$ and $s=0,2 \mathrm{~m}$, being $s$ the distance between the centre of two adjacent cables.

TABLE II. Sheath currents induced in example 1

\begin{tabular}{ccc} 
Sheath currents & $s=0.1 \mathrm{~m}$ & $s=0.2 \mathrm{~m}$ \\
\hline $\mathrm{I}_{\mathrm{R}}(\mathrm{A})$ & $45.89^{-131.44^{\circ}}$ & $56.82^{-134.94^{\circ}}$ \\
$\mathrm{I}_{\mathrm{S}}(\mathrm{A})$ & $33.84^{130.22^{\circ}}$ & $49.39^{120.41^{\circ}}$ \\
$\mathrm{I}_{\mathrm{T}}(\mathrm{A})$ & $52.92^{9.32^{\circ}}$ & $65.17^{-2.09^{\circ}}$ \\
\hline
\end{tabular}

From table II it can be deduced that by increasing the distance between the conductors, the mutual inductance between the conductors also increases (due to an increase of the sheath induced voltage) and it induces an increase of the sheath currents.

\subsection{Example 2}

In this example, it has been considered a three-phase flat line with a single conductor in each phase $(p=1)$, with configuration SRT and an intensity of $100 \mathrm{~A}$. The results of the simulations are shown in table III.

TABLE III. Sheath currents induced in example 2

\begin{tabular}{ccc}
\hline Sheath currents & $s=0.1 \mathrm{~m}$ & $s=0.2 \mathrm{~m}$ \\
\hline $\mathrm{I}_{\mathrm{R}}(\mathrm{A})$ & $33.84^{-109.78^{\circ}}$ & $49.39^{-119.59^{\circ}}$ \\
$\mathrm{I}_{\mathrm{S}}$ (A) & $52.92^{129.32^{\circ}}$ & $65.17^{117.91^{\circ}}$ \\
$\mathrm{I}_{\mathrm{T}}$ (A) & $45.89^{-11.44^{\circ}}$ & $56.82^{-14.94^{\circ}}$ \\
\hline
\end{tabular}

\subsection{Example 3}

In this example, it has been considered a three-phase flat line with a single conductor in each phase $(p=1)$, with configuration STR and an intensity of $100 \mathrm{~A}$. The results of the simulations are shown in table IV.

TABLE IV. Sheath currents induced in example 3

\begin{tabular}{ccc}
\hline Sheath voltages & $s=0.1 \mathrm{~m}$ & $s=0.2 \mathrm{~m}$ \\
\hline $\mathrm{I}_{\mathrm{R}}(\mathrm{A})$ & $52.92^{-110.68^{\circ}}$ & $65.17^{-122.09^{\circ}}$ \\
$\mathrm{I}_{\mathrm{S}}(\mathrm{A})$ & $45.89^{108.56^{\circ}}$ & $56.82^{105.06^{\circ}}$ \\
$\mathrm{I}_{\mathrm{T}}(\mathrm{A})$ & $33.84^{10.22^{\circ}}$ & $49.39^{0.41^{\circ}}$ \\
\hline
\end{tabular}

\subsection{Example 4}

In this example, it has been considered a three-phase flat line with two conductors in each phase $(p=2)$, with configuration $R_{1} S_{1} T_{1} R_{2} S_{2} T_{2}$ and an intensity of $100 \mathrm{~A}$ per phase. The results of the simulations are shown in tables $\mathrm{V}$ and VI.

TABLE V. Conductors currents computed form example 4

\begin{tabular}{ccc}
\hline Conductor currents & $s_{R I S I}=0.1 \mathrm{~m}$ & $s_{R I S I}=0.2 \mathrm{~m}$ \\
\hline $\mathrm{I}_{\mathrm{R}, 1}$ (A) & $46.57^{8.15^{\circ}}$ & $48.51^{6.40^{\circ}}$ \\
$\mathrm{I}_{\mathrm{R}, 2}$ (A) & $54.30^{-6.98^{\circ}}$ & $52.07^{-5.96^{\circ}}$ \\
$\mathrm{I}_{\mathrm{S}, 1}$ (A) & $48.09^{-122.11^{\circ}}$ & $48.21^{-122.07^{\circ}}$ \\
$\mathrm{I}_{\mathrm{S}, 2}$ (A) & $51.97^{-118.05^{\circ}}$ & $51.85^{-118.08^{\circ}}$ \\
$\mathrm{I}_{\mathrm{T}, 1}$ (A) & $57.39^{121.57^{\circ}}$ & $55.59^{119.99^{\circ}}$ \\
$\mathrm{I}_{\mathrm{T}, 2}$ (A) & $42.66^{117.89^{\circ}}$ & $44.41^{120.01^{\circ}}$ \\
\hline
\end{tabular}

TABLE VI. Sheath currents induced in example 4

\begin{tabular}{ccc}
\hline Sheath currrents & $S_{R I S I}=0.1 \mathrm{~m}$ & $s_{R I S I}=0.2 \mathrm{~m}$ \\
\hline $\mathrm{I}_{\mathrm{R}, 1}$ (A) & $20.51^{-126.24^{\circ}}$ & $27.07^{-130.71^{\circ}}$ \\
$\mathrm{I}_{\mathrm{R}, 2}$ (A) & $19.11^{-115.88^{\circ}}$ & $26.29^{-124.81^{\circ}}$ \\
$\mathrm{I}_{\mathrm{S}, 1}$ (A) & $17.75^{130.73^{\circ}}$ & $25.40^{120.94^{\circ}}$ \\
$\mathrm{I}_{\mathrm{S}, 2}$ (A) & $16.54^{129.08^{\circ}}$ & $24.35^{119.35^{\circ}}$ \\
$\mathrm{I}_{\mathrm{T}, 1}$ (A) & $19.69^{10.73^{\circ}}$ & $27.45^{-0.41^{\circ}}$ \\
$\mathrm{I}_{\mathrm{T}, 2}$ (A) & $23.43^{9.28^{\circ}}$ & $30.21^{-1.34^{\circ}}$ \\
\hline
\end{tabular}

\subsection{Example 5}

In this example, it has been considered a three-phase flat line with two conductors in each phase $(p=2)$, with configuration $R_{1} S_{1} T_{1} T_{2} S_{2} R_{2}$ and an intensity of $100 \mathrm{~A}$ per phase. The results of the simulations are shown in tables VII and VIII.

TABLE VII. Conductors currents computed from example 5

\begin{tabular}{ccc} 
Conductor currents & $s_{R I S I}=0.1 \mathrm{~m}$ & $s_{R I S I}=0.2 \mathrm{~m}$ \\
\hline $\mathrm{I}_{\mathrm{R}, 1}$ (A) & $50.00^{0^{\circ}}$ & $50.00^{0^{\circ}}$ \\
$\mathrm{I}_{\mathrm{R}, 2}$ (A) & $50.00^{0^{\circ}}$ & $50.00^{0^{\circ}}$ \\
$\mathrm{I}_{\mathrm{S}, 1}$ (A) & $50.00^{-120.00^{\circ}}$ & $50.00^{-120.00^{\circ}}$ \\
$\mathrm{I}_{\mathrm{S}, 2}$ (A) & $50.00^{-120.00^{\circ}}$ & $50.00^{-120.00^{\circ}}$ \\
$\mathrm{I}_{\mathrm{T}, 1}$ (A) & $50.00^{120.00^{\circ}}$ & $50.00^{120.00^{\circ}}$ \\
$\mathrm{I}_{\mathrm{T}, 2}$ (A) & $50.00^{120.00^{\circ}}$ & $50.00^{120.00^{\circ}}$ \\
\hline
\end{tabular}

TABLE VIII. Sheath currents induced in example 5

\begin{tabular}{ccc} 
Sheath currents & $S_{R I S I}=0.1 \mathrm{~m}$ & $S_{R I S I}=0.2 \mathrm{~m}$ \\
\hline $\mathrm{I}_{\mathrm{R}, 1}$ (A) & $23.82^{-136.93^{\circ}}$ & $28.72^{-138.79^{\circ}}$ \\
$\mathrm{I}_{\mathrm{R}, 2}$ (A) & $23.82^{-136.93^{\circ}}$ & $28.72^{-138.79^{\circ}}$ \\
$\mathrm{I}_{\mathrm{S}, 1}$ (A) & $17.59^{131.84^{\circ}}$ & $25.30^{121.16^{\circ}}$ \\
$\mathrm{I}_{\mathrm{S}, 2}$ (A) & $17.59^{131.84^{\circ}}$ & $25.30^{121.16^{\circ}}$ \\
$\mathrm{I}_{\mathrm{T}, 1}$ (A) & $42.98^{47.32^{\circ}}$ & $34.80^{-4.50^{\circ}}$ \\
$\mathrm{I}_{\mathrm{T}, 2}$ (A) & $42.98^{47.32^{\circ}}$ & $34.80^{-4.50^{\circ}}$ \\
\hline
\end{tabular}

\subsection{Example 6}

In this example, it has been considered a three-phase flat line with two conductors in each phase $(p=2)$, with configuration $R_{1} R_{2} S_{1} S_{2} T_{1} T_{2}$ and an intensity of 100 A per phase. The results of the simulations are shown in tables IX and X. 
TABLE IX. Conductors currents computed form example 6

\begin{tabular}{ccc} 
Conductor currents & $s_{R I S I}=0.1 \mathrm{~m}$ & $s_{R I S I}=0.2 \mathrm{~m}$ \\
\hline $\mathrm{I}_{\mathrm{R}, 1}$ (A) & $42.15^{-0.71^{\circ}}$ & $44.75^{0.73^{\circ}}$ \\
$\mathrm{I}_{\mathrm{R}, 2}$ (A) & $57.86^{0.51^{\circ}}$ & $55.26^{-0.59^{\circ}}$ \\
$\mathrm{I}_{\mathrm{S}, 1}$ (A) & $42.30^{-134.49^{\circ}}$ & $43.26^{-127.74^{\circ}}$ \\
$\mathrm{I}_{\mathrm{S}, 2}$ (A) & $59.99^{-109.84^{\circ}}$ & $57.43^{-114.17^{\circ}}$ \\
$\mathrm{I}_{\mathrm{T}, 1}$ (A) & $55.37^{111.62^{\circ}}$ & $52.15^{113.47^{\circ}}$ \\
$\mathrm{I}_{\mathrm{T}, 2}$ (A) & $45.94^{130.12^{\circ}}$ & $48.56^{127.02^{\circ}}$ \\
\hline
\end{tabular}

TABLE X. Sheath currents induced in example 6

\begin{tabular}{ccc} 
Sheath currents & $s_{R I S I}=0.1 \mathrm{~m}$ & $S_{R I S I}=0.2 \mathrm{~m}$ \\
\hline $\mathrm{I}_{\mathrm{R}, 1}$ (A) & $32.81^{-144.77^{\circ}}$ & $35.89^{-147.39^{\circ}}$ \\
$\mathrm{I}_{\mathrm{R}, 2}$ (A) & $29.10^{-147.19^{\circ}}$ & $33.29^{-148.25^{\circ}}$ \\
$\mathrm{I}_{\mathrm{S}, 1}$ (A) & $28.81^{122.23^{\circ}}$ & $33.76^{112.39^{\circ}}$ \\
$\mathrm{I}_{\mathrm{S}, 2}$ (A) & $23.61^{112.02^{\circ}}$ & $30.18^{107.18^{\circ}}$ \\
$\mathrm{I}_{\mathrm{T}, 1}$ (A) & $37.10^{-5.54^{\circ}}$ & $41.22^{-14.12^{\circ}}$ \\
$\mathrm{I}_{\mathrm{T}, 2}$ (A) & $39.37^{-11.70^{\circ}}$ & $42.42^{-18.04^{\circ}}$ \\
\hline
\end{tabular}

\subsection{Example 7}

In this example, it has been considered a three-phase double-row line with two conductors in each phase ( $p=$ 2), with configuration $R_{l} S_{I} T_{1}$

$$
R_{2} S_{2} T_{2}
$$

and a phase current of $100 \mathrm{~A}$.

The results of the simulations are shown in tables XI and XII.

TABLE XI. Conductors currents computed form example 7

\begin{tabular}{ccc}
\hline Conductor currents & $\begin{array}{c}s_{R I S I}=s_{R I R 2}= \\
0.1 \mathrm{~m}\end{array}$ & $\begin{array}{c}s_{R I S I}=s_{R I R 2}= \\
\end{array}$ \\
\hline $\mathrm{I}_{\mathrm{R}, 1}$ (A) & $50.00^{0^{\circ}}$ & $50.00^{0^{\circ}}$ \\
$\mathrm{I}_{\mathrm{R}, 2}$ (A) & $50.00^{0^{\circ}}$ & $50.00^{0^{\circ}}$ \\
$\mathrm{I}_{\mathrm{S}, 1}$ (A) & $50.00^{-120.00^{\circ}}$ & $50.00^{-120.00^{\circ}}$ \\
$\mathrm{I}_{\mathrm{S}, 2}$ (A) & $50.00^{-120.00^{\circ}}$ & $50.00^{-120.00^{\circ}}$ \\
$\mathrm{I}_{\mathrm{T}, 1}$ (A) & $50.00^{120.00^{\circ}}$ & $50.00^{120.00^{\circ}}$ \\
$\mathrm{I}_{\mathrm{T}, 2}$ (A) & $50.00^{120.00^{\circ}}$ & $50.00^{120.00^{\circ}}$ \\
\hline
\end{tabular}

TABLE XII. Sheath currents induced in example 7

\begin{tabular}{ccc} 
Sheath currents & $\begin{array}{c}s_{R I S I}=s_{R I R 2}= \\
0.1 \mathrm{~m}\end{array}$ & $\begin{array}{c}s_{R I S I}=s_{R I R 2}= \\
0.2 \mathrm{~m}\end{array}$ \\
\hline $\mathrm{I}_{\mathrm{R}, 1}(\mathrm{~A})$ & $27.10^{-141.63^{\circ}}$ & $31.12^{-143.13^{\circ}}$ \\
$\mathrm{I}_{\mathrm{R}, 2}(\mathrm{~A})$ & $27.10^{-141.63^{\circ}}$ & $31.12^{-143.13^{\circ}}$ \\
$\mathrm{I}_{\mathrm{S}, 1}$ (A) & $19.28^{127.32^{\circ}}$ & $26.54^{117.94^{\circ}}$ \\
$\mathrm{I}_{\mathrm{S}, 2}$ (A) & $19.28^{127.32^{\circ}}$ & $26.54^{117.94^{\circ}}$ \\
$\mathrm{I}_{\mathrm{T}, 1}$ (A) & $32.97^{2.59^{\circ}}$ & $37.63^{-7.28^{\circ}}$ \\
$\mathrm{I}_{\mathrm{T}, 2}$ (A) & $32.97^{2.59^{\circ}}$ & $37.63^{-7.28^{\circ}}$ \\
\hline
\end{tabular}

\subsection{Example 8}

In this example, it has been considered a three-phase double-row line with two conductors in each phase $(p=$ 2), with configuration $R_{l} S_{I} T_{1}$

$$
T_{2} S_{2} R_{2}
$$

and a phase current of $100 \mathrm{~A}$.

The results of the simulations are shown in tables XIII and XIV.
TABLE XIII. Conductors currents computed form example 8

\begin{tabular}{ccc} 
Conductor currents & $\begin{array}{c}s_{R I S I}=s_{R I T 2} \\
=0.1 \mathrm{~m}\end{array}$ & $\begin{array}{c}s_{R I S I}=s_{R I T 2} \\
=0.2 \mathrm{~m}\end{array}$ \\
\hline $\mathrm{I}_{\mathrm{R}, 1}$ (A) & $50.00^{0^{\circ}}$ & $50.00^{0^{\circ}}$ \\
$\mathrm{I}_{\mathrm{R}, 2}$ (A) & $50.00^{0^{\circ}}$ & $50.00^{0^{\circ}}$ \\
$\mathrm{I}_{\mathrm{S}, 1}$ (A) & $50.00^{-120.00^{\circ}}$ & $50.00^{-120.00^{\circ}}$ \\
$\mathrm{I}_{\mathrm{S}, 2}$ (A) & $50.00^{-120.00^{\circ}}$ & $50.00^{-120.00^{\circ}}$ \\
$\mathrm{I}_{\mathrm{T}, 1}$ (A) & $50.00^{120.00^{\circ}}$ & $50.00^{120.00^{\circ}}$ \\
$\mathrm{I}_{\mathrm{T}, 2}$ (A) & $50.00^{120.00^{\circ}}$ & $50.00^{120.00^{\circ}}$ \\
\hline
\end{tabular}

TABLE XIV. Sheath currents induced in example 8

\begin{tabular}{ccc}
\hline Sheath currents & $s_{R I S I}=0.1 \mathrm{~m}$ & $s_{R I S I}=0.2 \mathrm{~m}$ \\
\hline $\mathrm{I}_{\mathrm{R}, 1}$ (A) & $18.77^{-110.69^{\circ}}$ & $26.21^{-120.71^{\circ}}$ \\
$\mathrm{I}_{\mathrm{R}, 2}$ (A) & $18.77^{-110.69^{\circ}}$ & $26.21^{-120.71^{\circ}}$ \\
$\mathrm{I}_{\mathrm{S}, 1}$ (A) & $19.28^{127.32^{\circ}}$ & $26.54^{117.94^{\circ}}$ \\
$\mathrm{I}_{\mathrm{S}, 2}$ (A) & $19.28^{127.32^{\circ}}$ & $26.54^{117.94^{\circ}}$ \\
$\mathrm{I}_{\mathrm{T}, 1}$ (A) & $18.46^{6.94^{\circ}}$ & $25.84^{-2.03^{\circ}}$ \\
$\mathrm{I}_{\mathrm{T}, 2}$ (A) & $18.46^{6.94^{\circ}}$ & $25.84^{-2.03^{\circ}}$ \\
\hline
\end{tabular}

\section{Graphical summary of the results obtained}

In this section, it is shown a graphical summary of the results obtained in this work.

Figure 4 shows a comparative graph showing the conductors currents for the five examples explained above. The calculations of this example have been carried out by assuming a distance between the centre of adjacent conductors of $s=0,1 \mathrm{~m}$.

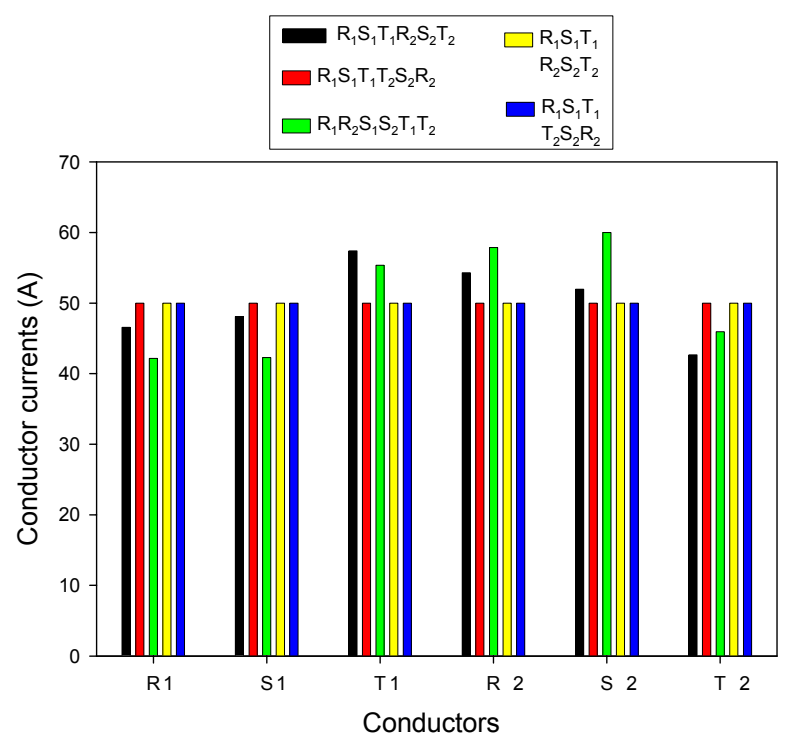

Figure 4. Comparative graph of the conductors currents for the different examples analyzed $(s=0,1 \mathrm{~m})$.

From figure 4 it can be deduced that configurations that allow to balance perfectly the conductors currents are the shown below:

$$
\begin{array}{lll}
R_{1} S_{1} T_{1} T_{2} S_{2} R_{2} & R_{1} S_{1} T_{1} & R_{1} S_{1} T_{1} \\
& R_{2} S_{2} T_{2} & T_{2} S_{1} R_{2}
\end{array}
$$

Figure 5 shows a comparative plot of the induced sheath currents for the five examples explained above. The calculation of this example have been carried out by assuming a distance between the centre of adjacent conductors of $s=0,1 \mathrm{~m}$. 


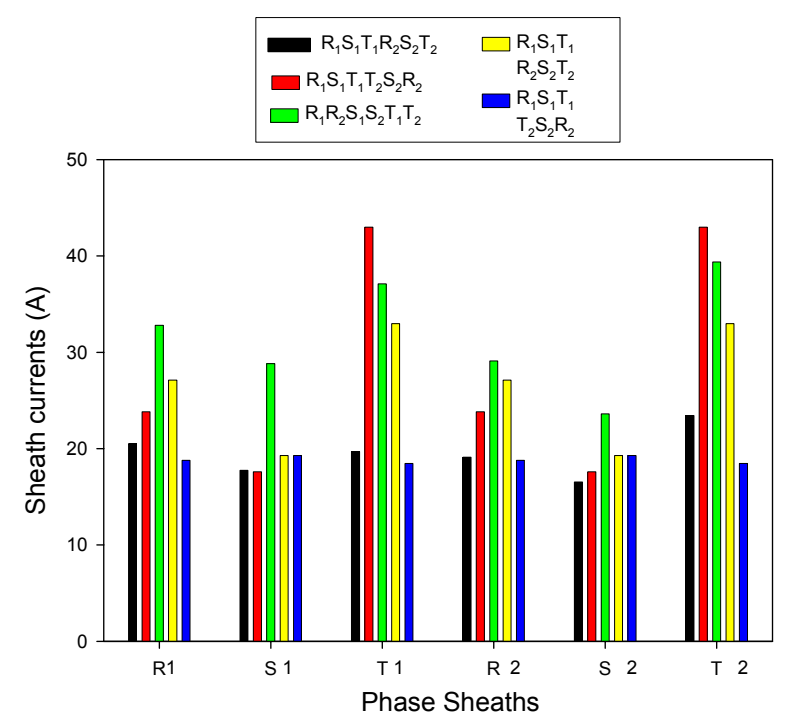

Figure 5. Comparative plot of the sheath induced currents for the different examples analyzed $(s=0,1 \mathrm{~m})$.

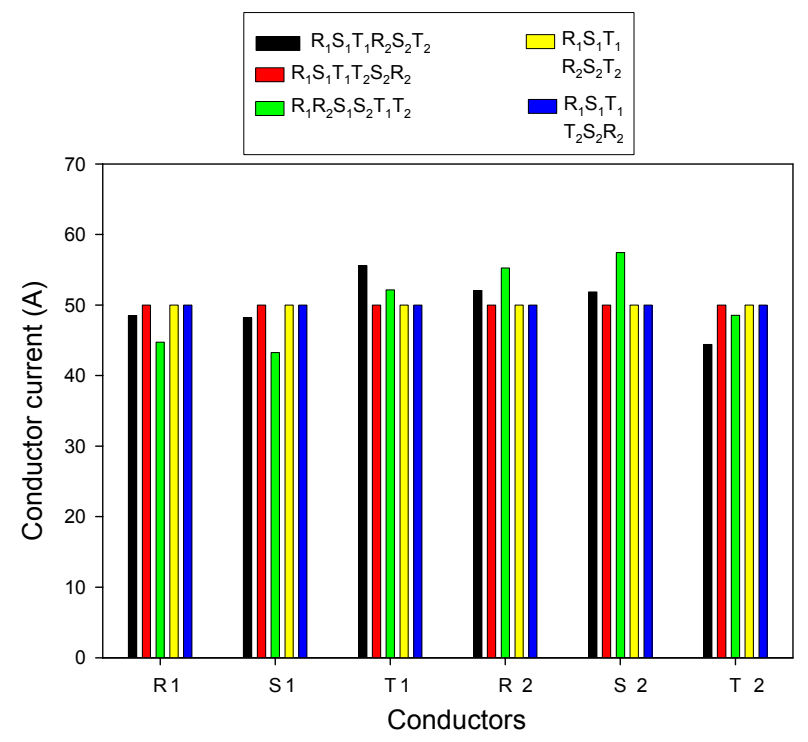

Figure 6. Comparative graph of the conductors currents for the different examples analyzed $(s=0,2 \mathrm{~m})$.

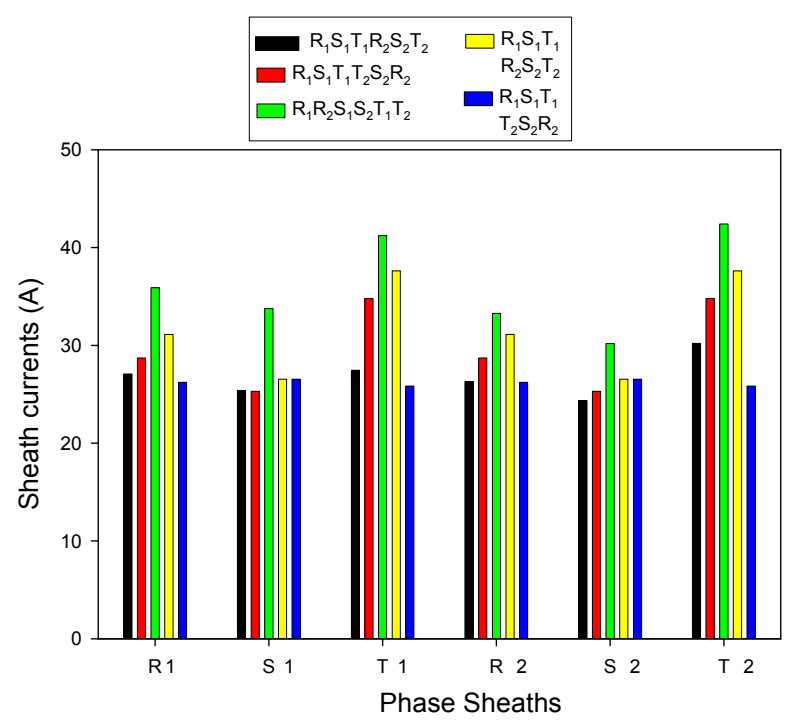

Figure 7. Comparative plot of the sheath induced currents for the different examples analyzed $(s=0,2 \mathrm{~m})$.
Figure 6 shows a comparative graph showing the conductors currents for the five examples explained above. The calculations of this example have been carried out by assuming a distance between the centre of adjacent conductors of $s=0,2 \mathrm{~m}$.

Figure 7 shows a comparative plot of the induced sheath currents for the five examples explained above. The calculation of this example have been carried out by assuming a distance between the centre of adjacent conductors of $s=0,1 \mathrm{~m}$.

\section{Conclusions}

Once the study has been realized, the following conclusions can be deduced:

- It has been shown that the geometry of the line, the gap between conductors and the electric and geometric parameters of the conductors have an important effect on the circulating sheath currents values.

- The circulating currents create a magnetic field which adds to the magnetic field generated by the central conductor. The resultant magnetic field usually is lower than the magnetic field generated by the central conductor.

- The reduction factor of the magnetic field depends on the geometry of the power line and the electric parameters of the cable.

- When the gap between the axes increases, also increase the sheath circulating currents. This fact produces a higher reduction of the total magnetic field generated by the power line.

\section{References}

[1] IEC 287-1-1: "Electric cables-calculation of the current rating, part 1: current rating equations (100\% load factor) and calculation of losses, section 1: general". IEC publication 287, 1994.

[2] ANSI/IEEE Std 575-1 988, IEEE Guide for the Application of Sheath-Bonding Methods for SingleConductor Cables and the Calculation of Induced Voltages and Currents in Cable Sheaths.

[3] J.S. Barrett, G.J.Anders. "Circulating current and hysteresis losses in screens, sheaths and armour of electric power cables-mathematical models and comparison with IEC Standard 287”. IEE Proc.-Sei. Meas. Technol., Vol. 144, No. 3, pp. 101-110, May 1997

[4] Peter Graneau. "Underground power transmission. The science, technology \& economics of high voltage cables”. Ed. John Wiley \& Sons, 1979.

[5] Manuel Llorente Antón. "Cables eléctricos aislados. Descripción y aplicaciones practices". Ed. Paraninfo, 1994..

[6] Víctor Sierra Madrigal, Alfonso Sansores Escalante. "Manual técnico de cables de energía". Ed. Mc Graw Hill, $2^{\text {a }}$ Edición, 1984

[7] Enrique Ras. "Teoría de líneas eléctricas". Ed. Marcombo 1986

[8] Jordi-Roger Riba Ruiz, Xavier Alabern Morera. "Effects of the circulating sheath currents in the magnetic field generated by an underground power line”. ICREPQ'06. Palma de Mallorca, 2006. 